\title{
The Difference of the Impact of Elective Cholecystectomy Surgery in the Immune Response
}

\section{Rosamaria Rodrigues Gomes, Manoel Messias Lima Neto, Ayrton Silva Alves, Cristiane Monteiro da Cruz}

Medical School, Centro Universitário Cesmac, Maceió, Brazil

Email: rosamaria.rg@gmail.com

How to cite this paper: Gomes, R.R., Neto, M.M.L., Alves, A.S. and da Cruz, C.M. (2018) The Difference of the Impact of Elective Cholecystectomy Surgery in the Immune Response. Surgical Science, 9, 243-247. https://doi.org/10.4236/ss.2018.98029

Received: March 28, 2018

Accepted: August 11, 2018

Published: August 14, 2018

Copyright $\odot 2018$ by authors and Scientific Research Publishing Inc. This work is licensed under the Creative Commons Attribution International License (CC BY 4.0).

http://creativecommons.org/licenses/by/4.0/

c) (i) Open Access

\begin{abstract}
Introduction: The inflammatory response is essential to initiate the healing process, and in this response there is an increase in white blood cells and pro-inflammatory compounds. C reactive proteins (CRP), together with the blood leukocyte count, have been used to study the immune response. Due to the risk of infection and exacerbated inflammatory response of the patients undergoing surgical procedure, it is relevant to investigate the pre and postoperative inflammatory response of those individuals. Objective: To determine the difference in the impact of elective cholecystectomy surgery on the patient's immune response. Methods: The present study was cross-sectional, where a group included patients who underwent elective cholecystectomy procedure. Patients who were pregnant, under 18 years, of indigenous communities or with other conditions that depress the immune system, as well as those on immunosuppressive medications, were excluded. Results: CRP and leukocyte counts indicated a mean increase of 5.97-fold (95\% CI 3.76 to 8.34 , SD 6.98) and 1.97-fold (95\% CI 1.71 to 2.24 , SD 1.97) respectively, both being evaluated before and after surgery. Discussion: In the present study, to avoid a possible methodological bias, it was chosen to evaluate the patients submitted to videolaparoscopic cholecystectomy only and the hypothesis was confirmed that there is an increase in CRP and leukocyte count as a response to surgical trauma. Conclusion: There was an elevation of the inflammatory markers in patients submitted to surgical trauma when comparing the exams collected in the preoperative period and after the surgical aggression.
\end{abstract}

\section{Keywords}

Cholecystectomy, Inflammation, Leukocytes, C-Reactive Protein 


\section{Introduction}

There are two major concerns when we subject the patient to surgical aggression: the severe systemic inflammatory response syndrome (SIRS) and infection, both are accompanied by the mobilization of massive amounts of immature neutrophils from the bone marrow into the circulation, triggering a cascade of reactions, which results in the synthesis of pro-inflammatory compounds [1].

The early immune response in surgical trauma is associated with the activation of innate immunity. C-reactive protein (CRP) is an acute phase inflammatory marker produced in the liver and, like white blood cell count, has been used as a study tool in assessing the immune response of patients undergoing surgical trauma. It has been seen that the greater the tissue damage caused by the procedure, the greater the elevation of this marker in plasma [2].

The inflammatory response, secondary to surgical trauma or not, associated with the activation of innate immunity, aims at reducing tissue damage, removing dead cell debris and initiating the healing process [3]. The patient submitted to the surgical process must be accompanied with caution, since this individual will present mechanisms that will hamper the recovery process [4]. Thus, it is relevant to investigate the pre and postoperative inflammatory response in patients submitted to the surgical procedure.

\section{Research Design and Methods}

The study was carried out at Hospital Maceió, Rua José Silveira Camerino, 815 Pinheiro Maceió/AL, 82-32152550, it was approved by the Ethics and Research Committee (CAAE: 69233317.2.0000.0039) and is a cross-sectional difference study. The sample presents a total of 36 patients who underwent elective cholecystectomy surgery. Pregnant women, those under 18 years of age, indigenous people and those with other pathologies that depress the immune system (such as cancer, AIDS, systemic lupus, rheumatoid arthritis and renal failure) were excluded, as well as those immunosuppressive medications (oral or venous corticosteroids, azathioprine, cyclosporine, mycophenolate mofetil and methotrexate).

\section{Statistical Method}

The statistical analysis was descriptive, and the $95 \%$ confidence interval for each estimated point was calculated.

\section{Results}

Among the evaluated patients, the mean age obtained was 40.97 years (95\% CI 36.26 to 45.69 ), with a predominance of females (72\% female, $95 \%$ CI 55.86 to $84.3 ; 27.78 \%$ male, $95 \%$ CI, 15.7 to 44.14 ), with only 3 diabetic patients (8.33\%, $95 \%$ CI 2.13 to 22.57 ) and 7 hypertensive patients (19.44\%, 95\% CI 9.45 to 35.33 ) (Table 1).

Regarding the values of CRP and leukocyte counts, it was observed that there 
was a mean increase of 5.97 times the CRP (95\% CI 3.76 to 8.34 and SD: 6.98), comparing pre and post-surgical an average increase of 1.97 times (95\% CI 1.71 to 2.24 and SD: 1.97 ) and a mean peak of $13,535 \mathrm{u} / \mathrm{L}$ (95\% CI 11,824 to 15,246 and SD: 5057) in the leukocyte count, also being evaluated before and after surgery (Table 2 and Table 3 ).

\section{Discussion}

Patients who undergo a surgical procedure exhibit elevation in inflammatory markers such as C-Reactive Protein (CRP) and white blood cell count. According to [5], CRP is one of the markers that allows a direct quantification of the

Table 1. Sociodemographic and clinical characteristics of the participants.

\begin{tabular}{|c|c|c|}
\hline & \multicolumn{2}{|c|}{ Frequency of men and women } \\
\hline & Women & Man \\
\hline Frequency & $(26 / 36)=0.72=72 \%$ & $(10 / 36)=0.28=28 \%$ \\
\hline \multirow[t]{3}{*}{$95 \% \mathrm{CI}$} & 55.86 to 84.30 & 15.70 to 44.14 \\
\hline & \multicolumn{2}{|c|}{ Frequency of hypertensive patients } \\
\hline & Hypertensive & Non Hypertensive \\
\hline Frequency & $(7 / 36)=0.1944=19.44 \%$ & $(29 / 36)=0.8056=80.56 \%$ \\
\hline \multirow[t]{3}{*}{$95 \% \mathrm{CI}$} & 9.45 to 35.33 & 64.67 to 90.55 \\
\hline & \multicolumn{2}{|c|}{ Frequency of diabetic patients } \\
\hline & Diabetic & Not Diabetic \\
\hline Frequency & $(3 / 36)=0.0833=8.33 \%$ & $(33 / 36)=0.9167=91.67 \%$ \\
\hline \multirow[t]{2}{*}{$95 \% \mathrm{CI}$} & 2.13 to 22.57 & 77.43 to 97.87 \\
\hline & \multicolumn{2}{|c|}{ Mean Age } \\
\hline Mean & \multicolumn{2}{|c|}{40.97} \\
\hline $95 \% \mathrm{CI}$ & \multicolumn{2}{|c|}{36.26 to 45.69} \\
\hline
\end{tabular}

Table 2. Pre and post-operative leukocyte count.

\begin{tabular}{ccc}
\hline & \multicolumn{2}{c}{ Leukocyte count } \\
\cline { 2 - 3 } & 7271.11 & Post-operative leukocytes \\
\hline Mean & Pre-operative leukocytes & $13,535.55$ \\
$95 \%$ CI & 6504.78 to 8037.44 & $11,824.22$ to $15,246.90$ \\
Standard deviation & 2264.91 & 5057.88 \\
\hline
\end{tabular}

Table 3. Pre and post-operative CRP count.

\begin{tabular}{ccc}
\hline & \multicolumn{2}{c}{ CRP count } \\
\cline { 2 - 3 } & Pre-operative CRP & Post-operative CRP \\
Mean & 1.97 & 5.97 \\
95\% CI & 1.71 to 2.24 & 3.76 to 8.34 \\
Standard deviation & 1.97 & 6.98 \\
\hline
\end{tabular}


acute phase inflammatory response. In this study, the values of CRP were increased approximately five times postoperatively, while in the present study the values found were similar, with an increase of 5.97 times after the surgical aggression.

According to [2], post-surgical values of CRP reached a mean peak of 27 $\mathrm{mg} / \mathrm{L}$, while post-surgical values of leukocytes reached an average peak of 11,000 $\mathrm{u} / \mathrm{L}$ disagreeing with the present study where values were around of $13,535 \mathrm{u} / \mathrm{L}$, both in patients submitted to the cholecystectomy procedure. Reference [2] and [6] they considered a possible bias that was to have used a heterogeneous sample regarding the type of surgical aggression.

In the present study, in order to minimize this bias, it was chosen to study the patients submitted to elective surgery of laparoscopic cholecystectomy and it was verified that these presented an increase in the measurements of CRP and leukocyte count, confirming that the surgical trauma triggers inflammatory activity, according to the literature.

Another important issue observed in this study was the predominance of women who underwent cholecystectomy. According to [7], cholecystolithiasis predominates in women in a ratio of 2:1 and some factors contribute to this, such as the use of oral contraceptives and multiple gestations, conditions not observed in this study.

The present study aimed to compare the inflammatory response of the diabetic patient to the non-diabetic one, since it is known that the patient with diabetes mellitus has a compromised immune system due to the disease, however, because the sampling technique was for convenience, there were no diabetic patients in sufficient numbers for comparison with statistical significance.

\section{Conclusion}

There was an elevation of the inflammatory markers PCR and leukocyte count in patients submitted to the surgical trauma of the videolaparoscopic cholecystectomy when comparing the exams collected in the immediate preoperative period and after 24 hours of the surgical aggression.

\section{Acknowledgements}

We, M.M.L.N. and A.S.A., would like to thank our mentor for pushing and helping us in every single step of this study. You have made us come this far and you have taught us a great deal, for that we are extremely grateful.

\section{Conflicts of Interest}

The authors declare no conflicts of interest regarding the publication of this paper.

\section{References}

[1] Dabrowska, A.M. and Stotwiński, R. (2014) The Immune Response to Surgery and 
Infection. Central European Journal of Immunology, 39, 532-537. https://doi.org/10.5114/ceji.2014.47741

[2] Watt, D.G., Horgan, P.G. and Mcmillan, D.C. (2015) Routine Clinical Markers of the Magnitude of the Systemic Inflammatory Response after Elective Operation: A Systematic Review. Surgery, 157, 362-380. https://doi.org/10.1016/j.surg.2014.09.009

[3] (1992) American College of Chest Physicians/Society of Critical Care Medicine Consensus Conference: Definitions for Sepsis and Organ Failure and Guidelines for the Use of Innovative Therapies in Sepsis. Critical Care Medicine, 20, 864-874. https://doi.org/10.1097/00003246-199206000-00025

[4] Lontchi-Yimagou, E., Sobngwi, E., Matsha, T.E. and Kengne, A.P. (2013) Diabetes Mellitus and Inflammation. Current Diabetes Reports, 13, 435-444.

https://doi.org/10.1007/s11892-013-0375-y

[5] Floros, T., Philippou, A., Nardakostas, D., Mantas, D. and Koutsilieris, M. (2016) The Growth Endocrine Axis and Inflammatory Responses after Laparoscopic Cholecystectomy. HORMONES, 15, 73-80.

[6] Kulkarni, O.P., Lichtnekert, J., Anders, H.J. and Mulay, S.R. (2016) The Immune System in Tissue Environments Regaining Homeostasis after Injury: Is (Inflammation) Always Inflammation? Hindawi Publishing Corporation Mediators of Inflammation, Cairo.

[7] Borges, M.C., Takeuti, T.D., Terra, G.A., Ribeiro B.M., Rodrigues-Júnior, V. and Crema E. (2016) Perfil Imunológico de Mulheres Submetidas à Colecistectomia Lalparoscópica Convencional e por Portal Único. Arquivos Brasileiros de Cirurgia Digestiva, 29, 164-169.

http://www.scielo.br/scielo.php?script=sci_arttext\&pid=S0102-67202016000300164 \&lng=en.\%20http://dx.doi.org/10.1590/0102-6720201600030009 https://doi.org/10.1590/0102-6720201600030009 